\title{
Various Methods of Knowledge Assessment during the Training of IT Specialists
}

\author{
Larisa Zaiceva $^{1}$, Natālija Prokofjeva ${ }^{2}$, Sabina Katalınikova ${ }^{3}$ \\ ${ }^{1-3}$ Department of Software Engineering, Riga Technical University, Latvia
}

\begin{abstract}
Nowadays requirements for training of qualified IT specialists constantly increase. These issues as well as possible solutions are discussed by both teachers and students on many seminars, forums and conferences. The paper studies different methods of students' knowledge control and computer systems that are used at the Faculty of Computer Science and Information Technology of Riga Technical University and demonstrates results of computer based students' knowledge control use. Since 2005, two experiments have been held at the Department of Software Engineering in order to evaluate the efficiency of e-course application. The aim of the study is to determine how the use of e-courses for the control of knowledge affects the quality of education during the course studies given that students do not perform all the control activities. The results have shown that the highest examination results are achieved by the students who have completed all the control activities. It proves the influence of use of e-courses for knowledge control on quality of education.
\end{abstract}

Keywords - Correlation, education, knowledge control, performance, statistical analysis.

\section{I.INTRODUCTION}

Due to the rising speed of scientific and technical progress, the amount of knowledge and skills necessary to contemporary specialists is continuously growing as its content is changing. This substantially increases the requirements of training of such specialists. The most important aspect of any educational activity is the system of knowledge quality control. The imbalance between the capacities of traditional methods of knowledge control and the amount of actual knowledge which contemporary society requires from university graduates indicates a problem in the higher education system. That is why the issues of computerbased knowledge control are of interest to many researchers in the areas of pedagogy, information technologies and beyond. Many scientific and scientifically-methodical international conferences (such as IEEE ICALT, IADIS eLearning, IASTED CATE, etc.) and e-journals [1], [2] are dedicated to research in computer-based learning and knowledge control. Researchers develop new methods of knowledge control and their implementation in the study process [3]-[5].

Nowadays, the fact is acknowledged that although technologies of computer-based learning have advanced greatly since the beginning of the 1990s (remote access to the Internet, multimedia and virtual reality in place of local networks), global problems in this area have remained virtually the same. These problems were summarised already in the end of 1980s in a series of monographs prepared with the active participation of researchers L.P. Leontiev, L.A. Rastrigin, L.V. Nicetsky, L.V. Zaiceva, L.P. Novicky and others of Riga Technical University (RTU) [6]-[8].

Different methods of computer-aided learning are used in preparing IT specialists at RTU at the moment, to wit: acquisition of reference information, distance learning, exercises and other means of knowledge control. By using computer systems, student knowledge control can be organised on all stages of the study process, thus substantially reducing the workload of teachers and the time spent to prepare the study materials, as well as to assure the objectivity of student knowledge control and evaluation. The article [9] aims to evaluate e-learning systems that are used in RTU from the perspective of their usefulness for administration of students' knowledge assessment. This research indicates that the use of e-learning systems has a positive effect on students' progress in studies. It increases their motivation, and they appreciate this kind of approach to learning process. The authors of paper [10] describe how the addition of substantial new components to the course "Algorithmization and Programming of Solutions" can raise the motivation of students, their interest in improving their own professional competence and quality of their education.

The present paper discusses the organisation and application of various methods of knowledge control in the preparation of IT specialists at Riga Technical University. It shows that computer based student knowledge control significantly affects the quality of learning.

\section{II.METHODS OF KNOWLEDGE CONTROL}

The basic methods of knowledge control used in contemporary educational practice are: oral examination, examination of written and graphic works, practical examination. All of these methods are imprecise and have subjective character of evaluation and irreproducibility (unrepeatability) of the results as their basic drawbacks. These drawbacks can lead to a situation where the teacher cannot gain real and objective view of the study process. In recent years, the work on perfecting control means and methods has substantially increased. Search for the new have brought to employment of controlling devices, complexes and computerbased learning and knowledge control systems [11]-[13].

Knowledge control can be considered from methodical, technical, legal and psychological point of view [14]. The methodical aspect includes control planning and organising, question type assignment and exercise selection, quiz question and exercise composition, grading criteria specification for each task and the whole of the quiz etc. The technical aspects 
involve automatic composition of quiz exercises based on the selected approach, selection and implementation of parameters of control in the knowledge control system, selection of control algorithms etc. Legal aspects have to do with the official recognition of control results (e.g., of distance exams) and with issuing corresponding diplomas and certificates. This aspect of knowledge control is directly connected to the technical one, which assures the objectivity of knowledge evaluation. Psychological aspects involve solving the problems of individual personality features in the learning process, as well as psychological regularities of perception, memory, thinking, attention and age characteristics of the students.

The process of computer-based knowledge control comprises there basic stages:

- selection of control questions from the database of exercise;

- delivery of the questions to the student and acquisition of his replies, possibly including feedback;

- grading the replies.

At the first stage the metadata of the exercises (difficulty, significance etc.) are defined according to the results of control experiment and the parameters of knowledge control are established (number of questions, answer time limit etc.). Metadata and parameters are then placed in the repository of the system (database, knowledge base and the model of the student) and used at the later stages. At the second stage, the acquired data are collected, analysed and preliminary processed. At the last stage, the work of the student is graded.

Computer-based methods of knowledge control can be classified as follows (Fig. 1) [15]-[17]:

- not adaptive methods. It means that during control process no information from student model is used;

- partly adaptive methods ensure that some of student characteristics and task parameters are considered;

- adaptive methods use the whole student model (ideal case) and learning material model.

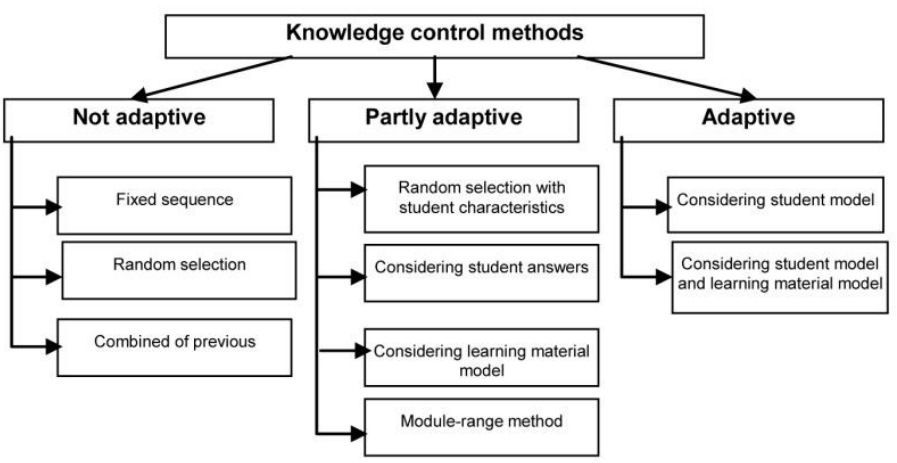

Fig. 1. Knowledge control methods.

Thus, in developing a system of computer-based knowledge control, it is necessary to [18]:

- determine the type of envisaged control (initial, current, final);

- formulate the aims of the test (e.g., control of knowledge of specific topic or section, control of residual knowledge after the completion of the course etc.) and accordingly define the content of the test;

- taking into account the envisaged goal, prepare the control material, i.e. develop the bank of exercises (questions) of different kinds and difficulty, presuming different comments on student answers etc.;

- develop the strategy of knowledge control (the strategy of knowledge control determines the mechanism of presenting the exercises and criteria of evaluation of student knowledge on the basis of a set of performed exercises);

- select methods of control organisation.

In the study process of RTU, different methods of knowledge control and computer systems are used to prepare IT specialists.

\section{III.ORGANISATION OF KNOWLEDGE CONTROL AT RTU}

RTU Faculty of Computer Science and Information Technology educates next bachelors and masters at the following three programmes: Automation and Computer Engineering, Computer Systems and Information Technologies. At the college, students are educated and trained according to the programme "Computer Systems". During first two years, all students of the Faculty study such subjects as Algorithmization and Programming of Solutions, Data Structures, Programming Languages, etc.

Riga Technical University uses the joint system named ORTUS based on Moodle that allows adding different materials, developing testing programmes with various question types and managing knowledge control. During the classes on computer sciences at RTU Department of Software Engineering, the joint university system is used as well as its own development - Learning Management System, which ensures work of four user classes: students, tutors, teaching material authors and administrator, as well provides adaptive learning and knowledge control e-courses.

RTU has developed the ORTUS portal, which provides administrative, scientific, and educational support for students and university staff. Part of this portal is a Moodle-based elearning environment that allows for creation of e-learning courses starting from uploading of different learning materials and finishing with developing tests and administering knowledge assessment activities.

The ORTUS system has been used in the study process since 2008. In this system, the teacher can create a test, assign the time and place of the examination, assign the number of attempts to pass the test. The test can be performed in the singular form (one attempt) and conducted during a class or performed at a distance as training (more than one attempt). It is possible to create tests from different categories and types of questions (in ORTUS 10 types of questions are used), consider the difficulty of the question, assign to difficult questions more points during grading. Comments for all kinds of questions are envisaged. The only drawback of the ORTUS environment is the fact that only one method of knowledge control is used in the system, namely, random selection. 
At the moment, 13 e-courses are implemented in the ORTUS system for the following study courses: "Programming Languages", "Data Structures" and "PHP Language for Web-application Development" (Table I). All these courses help the teacher to conduct different kinds of knowledge control during the semester and evaluate student performance at the exam. Thus, software packages "Pointers, Arrays and Strings" and "Lists, Stacks and Queues" ensure knowledge control over a given period in the study course "Data Structures" because they make it possible to evaluate the knowledge of particular topics, which later partially determine the final grade. The study course "PHP Language for Web-application Development" includes a test "HTML and CSS", which performs the initial control and enables the teacher to evaluate students' knowledge level before they begin to learn the PHP language. All the e-courses within the study course "Programming Languages" are performed in distance mode and they are also taken into consideration at the end of the course.

Learning Management System (LMS) [19] includes two modes that are directly connected to knowledge control: random selection of tasks and/or questions for control and training. Both can also be used for self-control. Random selection (RS) mode uses the non-adaptive control method. In this case, the number of questions for knowledge control in a group of students is defined by the teacher, who also determines how many exercises of varying difficulty (maximal, average, minimal) should be included in each set of

TABLE I

E-COURSES FOR KNOWLEDGE CONTROL

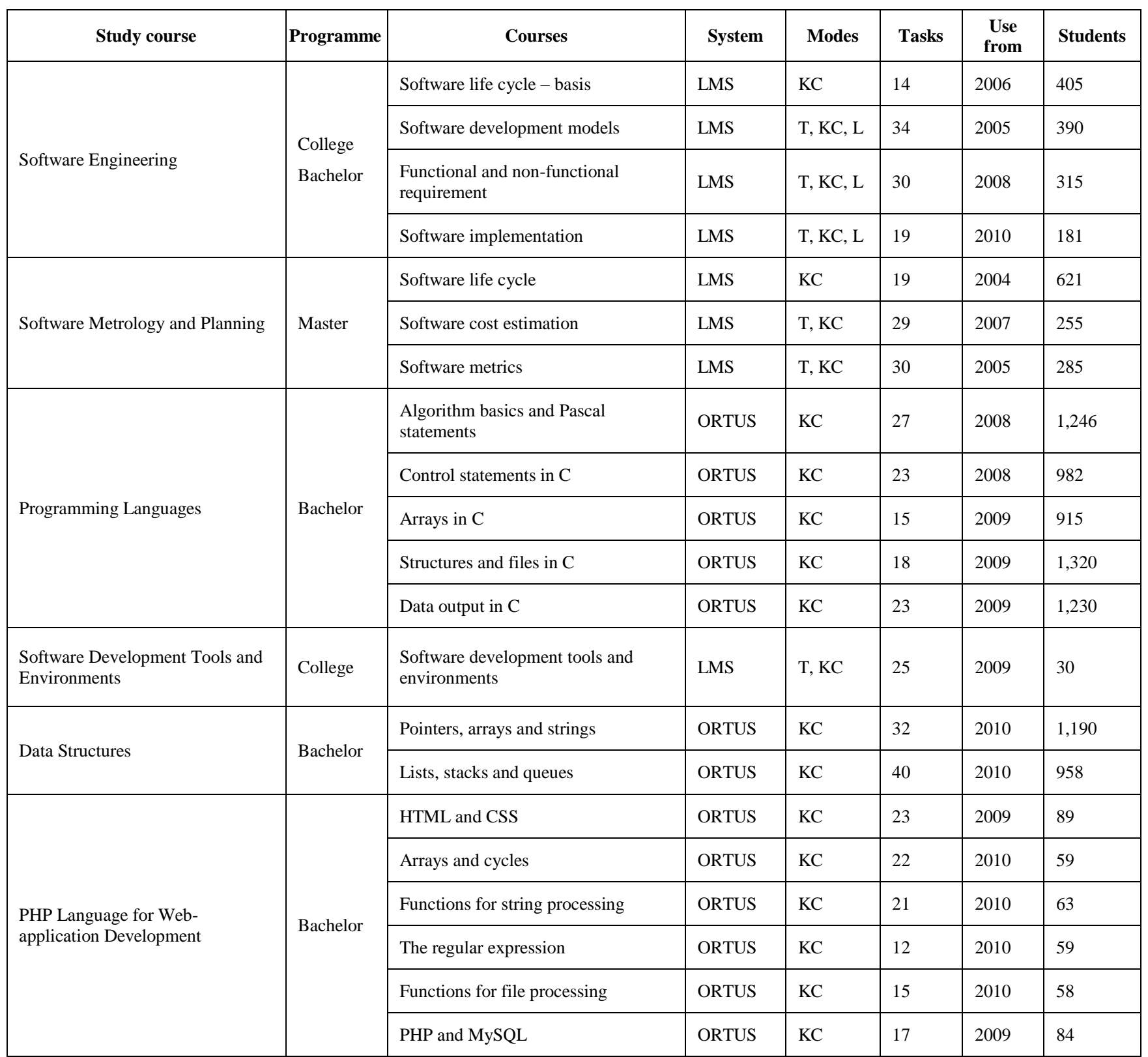


control questions. The teacher also specifies the type of comment that student receives in reply to his answers: concise (correct, not precise or wrong) or detailed with explanation of the mistake. In the case of self-control, students themselves choose and set these parameters. Depending on the choice, the training mode performs non-adaptive control (fixed sequence, Fig. 1), when students perform either all or a selected number of control exercises, or partially adapted control (considering students' answers), in which case the number of exercises given to students depends on how correctly students complete them. In this mode, the type of comment provided by the system can also be chosen. On finishing the test, students get a grade, which takes into consideration both correctness of answers and significance (maximal, average, minimal) and difficulty of questions.

At the present moment, LMS includes 8 e-courses in the following study course: "Software Engineering", "Software Metrology and Planning" and "Software Development Tools and Environments", which can be used in all described modes, as well as one e-course is available for college students in the study course "Programming Languages". At the initial stage of employment of LMS in 2004-2006, students could use the courses included in the system for selfcontrol, training and/or learning. Since 2007, student knowledge control in these courses has been compulsory and conducted during the practical classes. A student is offered 8 to 10 exercises for control. At the same time, in order to improve the received grade students are allowed to take the test repeatedly in 2 days' time. In this case, the grade is determined by the teacher. Students can also use other modes of the system at any time.

Table I provides information on the e-courses that are used for knowledge control: modes in use ( $\mathrm{KC}$ - knowledge control, $\mathrm{T}$ - training, L - learning), number of control exercises, number of students involved in the course etc.

Thus, for the education and training of IT professionals different approaches are used for monitoring students' knowledge and different computer control methods.

\section{IV.RESULTS OF E-COURSE USAGE}

The e-courses have successfully been applied by implementing different pedagogical approaches at the Department of Software Engineering of RTU since 2004.. Since then 2,915 students have used different e-courses for learning, training, knowledge and self-control in total for more than 480 hours. At the same time, each year $30-35 \%$ of the students work with the e-courses several (2-8) times.

Two experiments were held in order to evaluate the quality (efficiency) of the e-course application. The first experiment was performed during the time period of September 2005 till February 2008 where there were 237 participating students. Using the suggested method of the efficiency evaluation based on the students' current grades and their background knowledge, the absolute $(0.93)$ and relative efficiency $(20 \%)$ were calculated [20]. In the second experiment, there were 373 participants. The results were processed with two mathematical statistics methods: student t-criteria and Laplace function. The processed results proved that the e-courses enhanced learning efficiency (the significance level was $\alpha=0.05)$. The results showed that the grades of the students for the performed tasks on average increased by about $41 \%$ (exams $-26 \%$, laboratory activities $-56 \%$ ) [21]. During this study, the students were divided in two groups: 1 - used ecourses, 2 - did not use e-courses. All of the courses were included in the study.

The purpose of the study was to determine how the use of the e-courses for the control of knowledge affected the quality of education given that students did not perform all the control activities. Students could use e-courses as they wanted. As a result, students were divided into three groups: Group 1 - students used all the e-courses of the course; Group 2 - students used some e-courses; Group 3 - students did not use the e-courses (Table II). The study period was 20132016. For each group, the average exam score was calculated (in Latvia there is the 10-point grading scale). The study course "Software Development Tools and Environments" is not included in Table II because it has only one course and all of the students have used it.

TABLE II

E-COURSE USAGE

\begin{tabular}{|c|c|c|c|c|c|c|c|c|c|c|}
\hline \multirow{2}{*}{$\mathrm{nr}$} & \multirow{2}{*}{ Subject } & \multirow{2}{*}{$\begin{array}{c}\text { Total } \\
\text { number of } \\
\text { students }\end{array}$} & \multicolumn{3}{|c|}{ Student groups } & \multicolumn{3}{|c|}{ Marks } & \multirow{2}{*}{$\Delta \mathrm{M}_{1}$} & \multirow{2}{*}{$\Delta \mathrm{M}_{2}$} \\
\hline & & & Group1 & Group2 & Group3 & Group1 & Group2 & Group3 & & \\
\hline 1 & Software Engineering & 364 & 97 & 191 & 76 & 6.07 & 5.44 & 4.42 & 0.63 & 1.02 \\
\hline 2 & $\begin{array}{l}\text { Software Metrology and } \\
\text { Planning }\end{array}$ & 240 & 111 & 92 & 37 & 6.694 & 4.765 & 4.0 & 1.929 & 0.765 \\
\hline 3 & Programming Languages & 351 & 301 & 48 & 2 & 6.82 & 4.97 & 4.00 & 1.85 & 0.97 \\
\hline 4 & Data Structures & 486 & 440 & 41 & 5 & 7.44 & 4.71 & 4.12 & 2.73 & 0.59 \\
\hline 5 & $\begin{array}{l}\text { PHP Language for Web- } \\
\text { application Development }\end{array}$ & 29 & 25 & 3 & 1 & 7.40 & 6.33 & 4.00 & 1.07 & 2.33 \\
\hline
\end{tabular}


The results showed that the highest examination results in all of the courses were achieved by the students from Group 1 who completed all the control activities. They were followed by the students from Group 2, while the lowest scores were demonstrated by the students from Group 3 who did not perform any control activities. This relationship was observed during each year of the study period with only one exception: in 2016 in the study course "Software Engineering" $\Delta$ M1, i.e., the difference of the grades in Group 1 and Group 2 was negative (grades 6.19 and 7.18, respectively). The highest value obtained $\Delta \mathrm{M} 1=2.73$ was in the course "Data Structures" (there was also the smallest $\Delta \mathrm{M} 2=0.59$ ), but the lowest value (0.63) was in the course "Software Engineering".

The results in the form of a diagram are presented in Fig. 2.

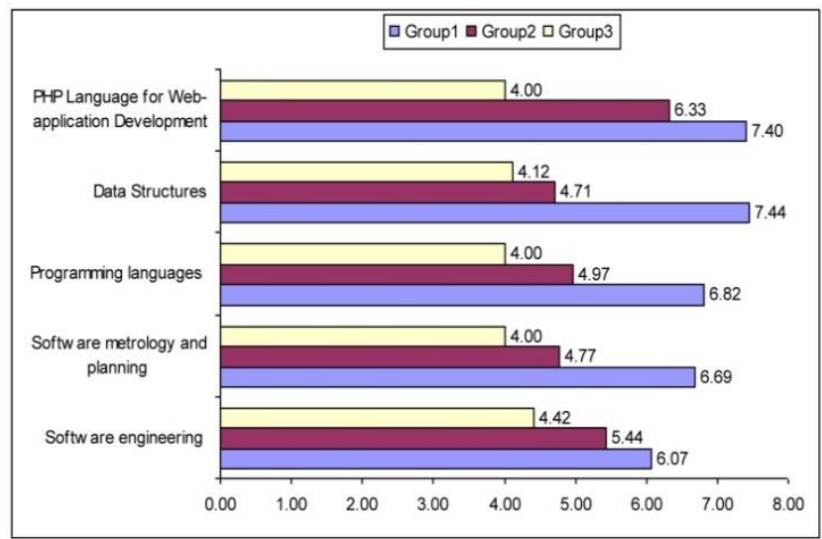

Fig. 2. The results of research.

In order to determine the usefulness of the e-course application and the interest of the students in their use, the survey was conducted. In 2015, the survey was offered to the students who were working with the e-courses in the LMS environment. The analysis of the survey showed the following: $50 \%$ of the students believed that the e-courses were useful because after using them it was easier to perform other tasks of the course such as lab activities; $42 \%$ of the students performed all the tasks included in the e-course; $39 \%$ - worked with the e-courses in order to prepare for the examinations; $84 \%$ - suggested that the e-courses should include different types of tasks (questions); and $75 \%$ of the students thought that one should create adaptive e-courses that would include theoretical material and assignments.

In 2016, the survey was conducted among the students that used e-courses in the ORTUS system; and there were 205 participants. The processed results of the survey are presented in Fig. 3. a)

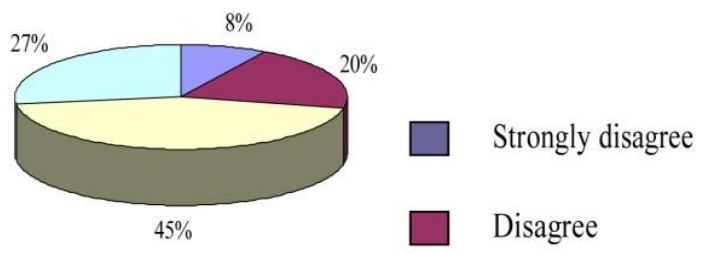

b)

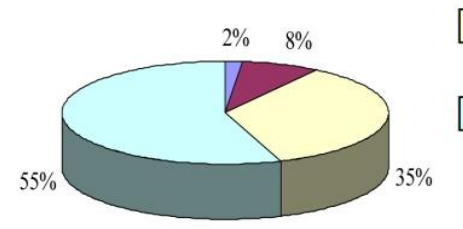

Agree

Strongly agree c)

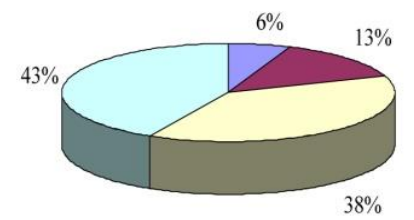

Fig. 3. Results of survey.

Most of the students found it useful to use ORTUS for the practical training (27\%) (Fig. 3a) as well for the teaching material (55\%) (Fig. 3b). Regarding the use of the e-courses for the knowledge and self-control the students expressed their views as follows: strongly agree $-43 \%$, tend to agree $-38 \%$ (Fig 3c).

\section{V.CONCLUSION}

Since 2005, 21 e-courses have been developed using different methods of knowledge control and successfully applied in the teaching process at the Department of Software Engineering of RTU. During this time period, more than 2,900 students have used different e-courses for learning, training and knowledge control. Since 2013 the experiment has been held to evaluate how the use of the e-courses for the knowledge control affects the quality of education. In total, there have been 1,470 participants.

The main results of the experiment are as follows:

1) 974 students (66\%, Group 1) have used all e-courses and 121 ( $8 \%$, Group 3) have not used e-courses for knowledge control;

2) the examination grades of Group 1 are better than for the other groups. In this case, the grades of Group 1 on average are higher by 1.64 comparing to that of Group 2 (where some e-courses have been used), and higher by 2.78 than that of Group 3;

3) the results of the survey conducted among the students have shown that a majority of the students (more than $50 \%$ ) are interested in the e-courses due to knowledge and selfcontrol, but $93 \%$ of the students find e-courses useful also for learning, training and examination preparation activities. 
Thus, the use of e-courses in the learning process can improve the quality of education and train qualified specialists in the field of IT technologies.

\section{REFERENCES}

[1] The Electronic Journal of e-Learning (EJEL) [Online]. Available http://www.ejel.org/main.html

[2] Journal of Educational Technology \& Society [Online]. Available: English version: http://www.ifets.info/, Russian version: http://ifets.ieee.org/russian/periodical/journal.html

[3] M. AL-Smadi, M. Höfler, C. Guetl, "An Enhanced Automated Test Item Creation Based on Learners Preferred Concept Space," International Journal of Advanced Computer Science and Applications, vol. 7, no. 3, pp. 397-405, Apr. 2016. https://doi.org/10.14569/ijacsa.2016.070354

[4] J.-Y. Lee, "A Dynamic System to Generate Randomly Relocated Multiple Choice Questions Using Ready-made Arrays," International Journal of Advanced Computer Science and Applications, vol. 9, no. 7, pp. 103-110, July 2015. https://doi.org/10.14257/ijseia.2015.9.7.11

[5] J. Grundspenkis, "Pros and Cons of Automated Knowledge Assessment Based on Concept Maps," in Proceedings of the 6th International Conference on Education and New Learning Technologies, Spain, Barcelona, 7-9 July, 2014. Burjassot: IATED Academy, 2014, pp. 3430-3439.

[6] L. Rastrigin and M. Erenshtein, Adaptive teaching with a model, Riga: Zinatne, 1986, 160 p. (in Russian).

[7] L. Nicetsky, "Requirements specification for development of the RPI computer-based teaching system first version," Riga: Riga Polytechnic Institute (RTU), 1977, 26 p. (in Russian)

[8] L. Zaiceva, L. Novitsky, and V. Gribkova, Computer-aided teaching systems development and using, Riga: Zinatne, 1989, 174 p. (in Russian)

[9] N. Prokofjeva, A. Anohina-Naumeca, O. Lebedeva. Administration of Knowledge Assessment at Riga Technical University, in Proceedings of the 8th International Multi-Conference on Computing in the Global Information Technology (ICCGI 2013), July 21-26, 2013, Nice, France, IARIA, pp.34-39, ISBN: 978-1-61208-283-7.

[10] N. Prokofyeva, M. Uhanova. Methodology of group work organisation for student learning performance improvement, in Environment. Technology. Resources: Proceedings of the 11th International Scientific and Practical Conference, Latvia, Rezekne, 15-17 June, 2017. (accepted for publication).

[11] R. T. Mora-García, M. F. Céspedes-López, R. Pérez-Sánchez, I. Álvarez-Canteli, "Method for Quality Evaluation of Digital Learning Tools," in Proceedings of 6th International Conference on Education and New Learning Technologies, Spain, Barcelona, 7-9 July, 2014 Burjassot: IATED Academy, 2014, pp. 2909-2918.

[12] A. Berkova, "The Efficiency of the Use of Computer-aided Assessment System in Mathematics," in Proceedings of the 13th International Conference "Efficiency and Responsibility in Education 2016", Czech Republic, Prague, 2-3 June, 2016, pp. 43-49.

[13] M. M. Fuad, D. Deb, J. Etim, and C. Gloster, "Using Interactive Exercise in Mobile Devices to Support Evidence-based Teaching and Learning," in Proceedings of the 2016 ACM Conference on Innovation and Technology in Computer Science Education, Arequipa, Peru, July 11-13, 2016, pp. 17-20.

[14] N. Prokofjeva, "The Methodical and Technical Aspects of Students Knowledge Control," in Proceedings of the 13th Education and Virtuality International Conference, VIRT - 2011, Ukraine - Yalta, 2011, pp. 263-272. (in Russian).

[15] L. Zaiceva and N. Prokofjeva, "Models and methods of the adaptive knowledge control," Educational Technology \& Society, vol. 7, no. 4, pp. 265-277, 2004. [Online]. Available: http://ifets.ieee.org/ russian/depository/v7_i4/html/1.html (in Russian).

[16] L. Zaiceva, C. Boule, N. Prokofjeva, "Knowledge control approaches in computer-assisted education," in Proceeding of The Eighth IASTED International Conference on Computers And Advanced Technology in Education, CATE - 2005, August 29-31, 2005, Oranjestad, Aruba, pp. 453-456.

[17] N. Prokofjeva, "Computer knowledge control models and methods," in Proceedings of First International Conference "Information Technologies in Education for All", ITEA - 2006, Ukraine, IRTC Kiev, 2006, pp. 231-240 (in Russian).
[18] N. Prokofjeva, "Strategies and Methods of Knowledge Control in Computer-based Training," International electronic journal "Educational Technology \& Society", pp. 378-392, 2010, ISSN 14364522. [Online]. Available: http://ifets.ieee.org/russian/ depository/v13_i1/html/11.htm (in Russian).

[19] L. Zaiceva, J. Bule, and U. Kuplis, "Advanced e-learning system development," in Proceeding of International Conference "Advanced Learning Technologies and Applications", ALTA-2003, Kaunas, Lithuania, 2003, pp. 14-18.

[20] L. Zaiceva, "E-courses using Results and Efficiency," in Proceedings of the $11^{\text {th }}$ IASTED International Conference "Computers and Advanced Technology in Education", CATE - 2008, September 29 - October 1, Crete, Greece, pp. 90-93.

[21] L. Zaiceva and J. Bule, "Pedagogical Strategies and Models for Elearning Courses Applying," in Proceedings of the IADIS International Conference e-Learning 2011, Vol. II, Rome, Italy, July 20 - 23, 2011, pp. 166-170.

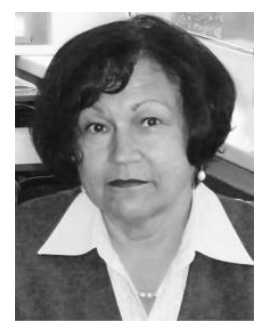

Larisa Zaiceva obtained the $D r$. sc. ing. degree in 1981. She is a Professor at the Faculty of Computer Science and Information Technology of Riga Technical University. The main field of research activity include e-learning systems (models, methods, technologies, evaluation of development and usage), software engineering, testing and reliability. Scientific activity: A member of the editorial board of Educational Technology \& Society (ISSN 1436-4522) within IEEE Learning Technology Task Force Eastern Europe Group; General Chair of the Joint International Conference on Engineering Education \& International Conference on Information Technology (ICEE/ICIT-2014 Riga), 2-6 June, Riga, etc. Contact information: Riga Technical University, Kalku Str. 1, Riga, LV-1050, Latvia; phone: +371 6089571.

E-mail: larisa.zaiceva@rtu.lv

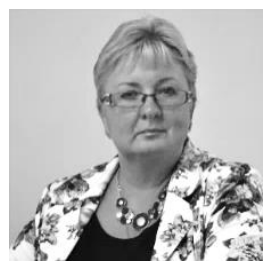

Natālija Prokofjeva obtained $D r$. sc. ing. degree in 2007. She is an Associate Professor of the Faculty of Computer Science and Information Technology of Riga Technical University. The main fields of research activity include e-learning systems (model, methods, technologies), modern Internet technologies. Scientific activity: A member of local organisation team of 2014 Joint International Conference on Engineering Education \& International Conference on Information Technology (ICEE/ICIT-2014 Riga), 2-6 June, Riga.

Contact information: Riga Technical University, Kalku Str. 1, Riga, LV-1050, Latvia; phone: +371 6089571.

E-mail: natalija.prokofjeva@rtu.lv

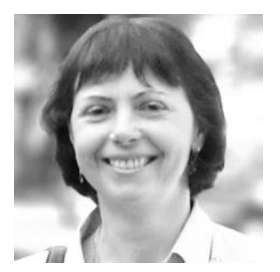

Sabina Katalninikova is currently a Doctoral student at Riga Technical University, Faculty of Computer Science and Information Technology. Her research interests include intelligent systems for collaborative learning. Scientific activity: A member of local organisation team of 2014 Joint International Conference on Engineering Education \& International Conference on Information Technology (ICEE/ICIT-2014 Riga), 2-6 June, Riga.

Contact information: Riga Technical University, Kalku Str. 1, Riga, LV-1050, Latvia; phone: +371 6089571.

E-mail: sabina.katalnikova@rtu.lv 